\title{
AMIZADE INTERCULTURAL DE ESTUDANTES NO CONTEXTO ESCOLAR BRASILEIRO DE FRONTEIRA SECA BRASIL-PARAGUAI ${ }^{1}$
}

\author{
INTERCULTURAL FRIENDSHIP OF STUDENTS IN THE BRAZIL-PARAGUAY \\ DRY BORDERS
}

Maria Luzia da Silva Santana

Doutora em Psicologia pela Universidade Católica de Brasília. santanapsi@gmail.com

\author{
Cláudia Cristina Fukuda \\ Doutora em Psicologia pela Universidade de Brasília. \\ claudiafukuda@hotmail.com
}

\begin{abstract}
Resumo: a amizade entre estudantes de culturas diferentes sugere a adoção da integração como estratégia de aculturação e, possivelmente, afeta a identificação do estudante estrangeiro com o país acolhedor. A partir desse pressuposto, esta pesquisa descreve as relações de amizade de estudantes brasileiros e paraguaios em uma turma de uma escola pública brasileira da fronteira seca da cidade de Ponta Porã, no Brasil, com Pedro Juan Caballero, no Paraguai. Participaram da pesquisa 32 estudantes do $7^{\circ}$ ano, que responderam a um Questionário de Dados Sociodemográficos, um Questionário de Amizade Intercultural na Escola e um Teste Sociométrico. Quanto à aproximação por amizade, observou-se a existência de subgrupos na sala de aula, escolhas mútuas para realizar tarefas conjuntamente, e também estudantes que não foram escolhidos. Embora a minoria dos estudantes falasse espanhol e guarani com seus amigos na escola, havia amizade entre estudantes de ascendência paraguaia, paraguaios e brasileiros, com escolhas mútuas entre eles.
\end{abstract}

Palavras-chave: Amizade. Escola de fronteira. Interculturalidade.

Abstract: Friendship between students of different cultures suggests the adoption of integration as an acculturation strategy and possibly affects the identification of the foreign student with the hosting country. This study describes the relations of Brazilian and Paraguayan students in a public school of the dry borders between the cities of Ponta Porã, in Brazil, and Pedro Juan Caballero, in Paraguay. 32 students aged 12 and 13 years old answered a sociodemographic questionnaire, a questionnaire about intercultural friendship at school, and a sociometric test. As a result, we observed the existence of subgroups in the classroom, as well as students who would pick each other as partners and students who did not get to be chosen for any work group. Though the minority of the students spoke Spanish and Guarani with their classmates, we identified friendship among Paraguayan descendants, Paraguayans, and Brazilian students, who would pick each other for work group.

Key-words: Friendship. School in the border. Interculturality.

\section{Para citar - (ABNT NBR 6023:2018)}

SANTANA, Maria Luzia da Silva; FUKUDA, Cláudia Cristina. Amizade intercultural de estudantes no contexto escolar brasileiro de fronteira seca Brasil-Paraguai. Eccos - Revista Cientifica, São Paulo, n. 52, p. 1-21, e8372, jan./mar. 2020. Disponível em: https://doi.org/10.5585/eccos.n52.8372.

\footnotetext{
${ }^{1}$ Este artigo faz parte da tese de doutorado não publicada em Psicologia da autora, orientada pela coautora.
} 


\section{Introdução}

O comportamento humano se desenvolve e se expressa em contextos culturais; assim, precisa ser compreendido a partir da cultura em que ocorre (DEBIAGGI, 2004). A psicologia intercultural é um ramo da psicologia que estuda as relações entre o contato intercultural e as reações psicológicas da pessoa (NETO, 2012a). Para Berry et al. (2002, p. 3), a psicologia intercultural também estuda as semelhanças e diferenças no “[...] funcionamento psicológico individual de vários grupos culturais e étnicos, e as relações entre variáveis psicológicas e socioculturais, variáveis ecológicas e biológicas, como também as mudanças progressivas nestas variáveis".

De forma geral, a psicologia intercultural compreende e estuda o processo de aculturação, que abrange os elementos culturais e psicológicos do encontro e da convivência de pessoas de culturas diferentes (BERRY, 1997b). A dimensão psicológica é denominada de "aculturação psicológica" em referência às transformações que a pessoa experimenta como resultado do contato com outras culturas (NETO, 2012a). As interações interculturais possibilitam à pessoa adotar diferentes padrões de aculturação, $\mathrm{o}$ que resulta em adaptações socioculturais e psicológicas (BERRY, 1997a).

A adaptação sociocultural refere-se à aprendizagem de competências sociais que possibilitam a interação com a nova cultura, incluindo lidar com as demandas do quotidiano e realizar eficazmente as atividades diárias (NETO, 2012b). Já a adaptação psicológica é expressa em nível individual; diz respeito ao impacto da aculturação na saúde mental dos envolvidos e inclui o bem-estar psicológico, a satisfação com a vida, a autoestima e o estresse presentes no processo de aculturação.

As estratégias de aculturação podem ser assimilação, separação, integração ou marginalização. A assimilação indica que o sujeito não deseja manter sua identidade cultural e busca interação estreita com a outra cultura. A separação é caracterizada pela manutenção da cultura original da pessoa e pela resistência em interagir com os membros da nova sociedade. A integração inclui uma inter-relação com as culturas, ou seja, acontece a manutenção tanto da cultura original como das interações cotidianas com outros grupos étnicos e culturais, participando da sociedade que acolhe o imigrante. E a marginalização é definida como a pouca possibilidade ou falta de interesse na manutenção da própria identidade e no estabelecimento de relações com os novos grupos, na maioria das vezes por razões de exclusão ou discriminação (SAM; BERRY, 2010). 
As relações interculturais são visíveis em instituições educativas localizadas na região de fronteira brasileira com outros países, a exemplo da fronteira seca entre a cidade de Ponta Porã (Brasil) e a de Pedro Juan Caballero (Paraguai), em que os limites territoriais são demarcados por apenas uma rua, a Avenida Internacional. Acontece um fluxo intenso de pessoas em ambos os lados dessa fronteira: há brasileiros utilizando os serviços ofertados no Paraguai e paraguaios no Brasil. Nas escolas de Ponta Porã, sobretudo as localizadas próximas à faixa de fronteira, observa-se um número considerável de estudantes brasileiros de ascendência paraguaia e de estudantes paraguaios, uma vez que eles geralmente têm dupla nacionalidade, pois foram registrados em ambos os países.

A presença de estudantes paraguaios nas escolas brasileiras não ocorre sem conflitos e antagonismos (BERGER, 2015a), inclusive ligados ao uso da língua materna. Em relação à educação bilíngue ou multilíngue nesses contextos de fronteira, Berger (2015a) observou que, mesmo sendo língua materna de muitas crianças e fazendo parte do repertório linguístico de alguns dos educadores, o espanhol era abordado na escola como língua estrangeira, tanto em termos curriculares quanto no âmbito das práticas pedagógicas. Já a língua guarani, que constituía o repertório linguístico de grande parte dos estudantes, estava ausente do sistema escolar e da organização curricular; ainda assim, era usada, sobretudo "em recortes espaço-temporais como o horário de recreação, intervalo, entrada/saída dos alunos nas escolas" (BERGER, 2015b, p. 149).

Da mesma forma, Pereira (2014) aponta que, na análise da realidade educativa na fronteira entre Ponta Porã e Pedro Juan Caballero, apesar de os professores e as autoridades escolares terem reconhecido a pluralidade cultural nas escolas, a pedagogia utilizada foi monolíngue por muitos anos. Para a autora, tal situação demanda ações específicas, que facilitem a inclusão das crianças e estudantes de origem estrangeira no contexto escolar brasileiro, com o reconhecimento e respeito a suas características culturais (PEREIRA, 2014).

Os aspectos culturais de cidades localizadas na região de fronteira requerem currículo e práticas educativas que acolham as diferenças dos estudantes, incluindo sua língua materna, seus costumes, suas crenças e seus saberes, que devem favorecer as relações interpessoais pautadas na ideia de cidadania global. A promoção da educação para a cidadania global busca desenvolver, nos estudantes, o reconhecimento e a apreciação das diferenças e identidades múltiplas por meio de habilidades para viver em 
um mundo caracterizado cada vez mais pela diversidade, incluindo cultura, língua, gênero, sexualidade e religião. Assim, busca-se promover conhecimentos, habilidades, valores e atitudes indispensáveis para respeitar as diferenças e conviver com os outros (UNESCO, 2016).

As investigações das relações de amizade ancoradas na perspectiva da ética e política (CARVALHO, 2015, 2010; CARVALHO; LUENGO, 2017, 2015), assim como a denominada "modernidade líquida" (SILVA, 2018), possibilitam sugerir que a relação de amizade entre os pares em sala de aula é um recurso relevante para estabelecer relações respeitosas e inclusivas no contexto escolar. Isso pode contribuir para a autonomia dos estudantes e para o desenvolvimento de relações interpessoais e interculturais positivas, marcadas pelo sentimento de solidariedade e cooperação. Assim, a amizade intercultural, especificamente entre estudantes imigrantes na escola, é importante para a sua integração e afeta a sua identificação com o país acolhedor (GARCIA; PENSO, 2016).

A amizade entre crianças de diferentes origens étnicas pode contribuir para o apoio pessoal e socioemocional dos envolvidos. $\mathrm{O}$ aspecto mais valioso da amizade intercultural parece ser o seu potencial de possibilitar uma relação de igualdade de status, além de favorecer recursos sociais e emocionais. Porém, pesquisas sinalizam que as relações de amizade intercultural são menos frequentes do que entre colegas de mesma origem étnica na escola, o que implica que essa variável continua sendo um fator na seleção de amigos (ABOUD; MENDELSON; PURDY, 2003).

A pesquisa de Aboud, Mendelson e Purdy (2003), realizada numa escola primária intercultural em Montreal, que atendia estudantes brancos e negros originários do Caribe e do Sudeste e sul asiático, examinou as relações entre pares, isto é, a interação entre os companheiros, as amizades mútuas, a estabilidade e as qualidades percebidas nos amigos em comum. Os achados apontaram que as crianças com atitudes menos tendenciosas e preconceituosas tinham mais companhias interativas e percepções mais positivas de seus amigos. Assim, em comparação com seus colegas de classe mais tolerantes, crianças brancas com níveis mais elevados de preconceito tenderam a excluir colegas de origem étnica diferente da sua, tiveram menos companheiros e classificaram sua amizade em níveis mais baixos de qualidade.

O estudo de Valdivia, Schneider e Carrasco (2016) observou a relação entre ajuste escolar, amizade e identificação entre a cultura de origem e a cultura acolhedora de 682 estudantes de seis escolas públicas de ensino médio na Catalunha, Espanha. Os resultados 
mostraram que as estratégias de aculturação, integração e assimilação são adaptativas, mas de diferentes maneiras, e que a identificação com a cultura de origem é um preditor significativo da amizade. A cultura acolhedora foi relacionada ao ajuste escolar, ou seja, os adolescentes imigrantes que chegavam à Catalunha não precisavam escolher entre manter suas culturas de origem e alcançar o apoio dos pares para o sucesso acadêmico (VALDIVIA; SCHNEIDER; CARRASCO, 2016).

Considerando a importância da amizade no processo de aculturação, o presente estudo busca contribuir para o conhecimento sobre a interculturalidade a partir da análise da amizade de estudantes paraguaios e brasileiros na escola. Para tanto, descreve as relações de amizade desses estudantes em uma turma de uma escola pública brasileira da fronteira seca de Ponta Porã, no Brasil, com Pedro Juan Caballero, no Paraguai.

Método

Participantes

Participaram da pesquisa 32 estudantes - 16 do sexo feminino e 16 do masculino de uma turma do $7^{\circ}$ ano do ensino fundamental, do turno matutino, de uma escola pública brasileira de Ponta Porã. Os estudantes tinham entre 12 e 13 anos. Onze estudantes declararam morar na cidade de Pedro Juan Caballero, mas eram brasileiros. Deles, um estudante do sexo masculino informou ser "brasiguaio"; os demais informaram ser brasileiros e residir no Brasil. Oito estudantes relataram falar o idioma guarani e/ou espanhol, quatro dos quais conversavam com seus amigos nesses idiomas. Os nomes dos estudantes foram substituídos por letras do alfabeto a fim de manter o sigilo e o anonimato, de $\mathrm{A}$ até $\mathrm{Z}$ e de AA até AM. No teste sociométrico, alguns respondentes mencionaram colegas ausentes (AJ, AM e AL).

\section{Instrumentos}

Questionário de dados sociodemográficos, contendo 15 questões sobre idade, sexo, ano escolar, turma, cidade de residência, nacionalidade, origem étnica do estudante e de seus pais, idiomas que falava e escrevia, e se já havia estudado em escolas situadas noutros países.

Questionário de amizade intercultural na escola, com 10 questões que possibilitaram a descrição do local onde o estudante conheceu o amigo, a língua em que 
conversavam, as brincadeiras favoritas dos amigos, os assuntos preferidos nas conversas e as atividades realizadas juntos na escola. Esse instrumento foi desenvolvido para esta pesquisa e considerou a escola como contexto propício ao estabelecimento de amizade entre colegas, haja vista que ali se desenvolvem várias atividades em grupo. Além disso, consideraram-se as línguas como elemento que, possivelmente, está presente em escolas que atendem estudantes de diferentes culturas.

Teste sociométrico, com 6 questões, que contemplou a eleição positiva de três colegas em ordem decrescente para realizar uma tarefa na sala de aula; a eleição negativa, em ordem decrescente, de três colegas com quem não realizar uma tarefa na sala; e, finalmente, uma eleição neutra, em ordem decrescente, de três colegas indiferentes para realizar uma atividade na turma (BUSTOS, 1979).

Esse teste é compreendido como um instrumento que torna possível estudar as estruturas sociais em decorrência das atrações e repulsas expressas no seio de um grupo (MORENO, 1994). Através dele, é identificada a posição social que cada pessoa ocupa num grupo em relação às preferências e rejeições que os integrantes demonstram. Por meio dessas informações, são construídos os mapas das relações entre a pessoa e o grupo (BUSTOS, 1979).

\section{Procedimentos para a coleta e análise dos dados}

A pesquisa foi aprovada pelo Comitê de Ética em Pesquisa da Universidade Federal de Mato Grosso do Sul (CEP/UFMS), conforme o parecer número 2.407.166. Realizaram-se visitas à sala de aula para apresentação da proposta de pesquisa, convite à participação, entrega e explicação do Termo de Consentimento Livre e Esclarecido (TCLE) e do Termo de Assentimento (TA), bem como agendamento dos dias para a devolução destes materiais e aplicação dos instrumentos.

Os instrumentos foram aplicados na própria sala de aula, em dois momentos. Em ambos, foi explicado aos estudantes o que era cada instrumento e como respondê-los. No primeiro momento, foi aplicado o questionário sociodemográfico e, no segundo, o questionário de amizade intercultural na escola e o teste sociométrico.

Foi feita uma análise descritiva dos dados do questionário sociodemográfico e do questionário de amizade intercultural na escola. A análise do teste sociométrico seguiu o 
teste desenvolvido por Moreno (1994). Na indicação das escolhas mútuas, usaram-se símbolos, sendo que os estudantes de ascendência paraguaia ou paraguaio e brasiguaio e os que falavam espanhol ou guarani com os amigos foram marcados com sinais. Utilizouse o programa $y E d$ Graph Editor para a construção dos sociogramas.

\section{Resultados e discussão}

Os 32 estudantes indicaram o local onde conheceram os amigos. Destes, 15 descreveram somente escola, 8 apontaram escola e vizinhança/bairro, 6 indicaram escola e outros 2 descreveram escola, vizinhança/bairro e outros, e 1 descreveu vizinhança/bairro e outros. Portanto, a escola foi o local mais indicado como favorecedor da relação de amizade dos estudantes. Essas relações ocorrem desde a educação infantil, sendo que, no ensino fundamental, continuam a representar um elemento importante de ajustamento da criança à escola. Muitas das relações de amizade são constituídas com os colegas de sala, e alguns relacionamentos são preservados mesmo quando há mudança para outros contextos escolares (GARCIA, 2005).

Os dados acerca da amizade intercultural dos estudantes apontam que, na sala de aula investigada, os estudantes gostavam de estudar e conversar com os melhores amigos e outros amigos; brincavam e passavam a hora do recreio com eles. Observou-se a cooperação na turma, pois a maioria dos estudantes relatou que emprestava material escolar para todos os colegas que pedissem. Somente três sinalizaram que emprestavam apenas para os melhores amigos, um emprestava para os amigos, e dois não emprestavam para ninguém.

A comunicação entre os amigos nessa turma acontecia principalmente na língua portuguesa: 28 apontaram o português; 2, o português e o espanhol (um deles explicou que, como morava no Paraguai, fala em espanhol com seus amigos); 1, o espanhol; e 1, o guarani com estudantes paraguaios ou de ascendência paraguaia.

Nesta pesquisa, as brincadeiras mais citadas entre amigos foram futebol, queimada, vôlei, esconde-esconde, jogos de celular e videogame. Nas conversas, eles falavam mais acerca de jogos, músicas, atividades e trabalhos escolares, a escola, "zoeira", outras coisas "para rir", músicas, vídeos do YouTube, garotos, garotas e namorados ou namoradas, moda e roupas. As atividades preferidas realizadas com os amigos na escola foram jogar futebol, queimada e vôlei, conversar, brincar, fazer as tarefas e atividades de aula, realizar trabalho em grupo, fazer bagunça (Tabela 1). 
Tabela 1 - Elementos de amizade entre estudantes

\begin{tabular}{lll}
\hline Brincadeiras preferidas & $\mathbf{N}$ & $\mathbf{\%}$ \\
\hline Brincadeiras e jogos com bola & 30 & 56,6 \\
Brincadeiras de grupo sem bola & 10 & 18,7 \\
Brincadeiras/jogos com equipamentos & 10 & 18,7 \\
eletrônicos & & \\
Andar de skate, bicicleta ou moto & 3 & 5,6 \\
Total & 53 & 100 \\
\hline Atividades realizadas na escola & $\mathbf{N}$ & $\mathbf{\%}$ \\
\hline Jogar bola & 19 & 40,4 \\
Realizar tarefas e trabalhos em grupo e estudar & 9 & 19,2 \\
Brincar & 8 & 17 \\
Conversar & 7 & 14,9 \\
Outras & 4 & 8,5 \\
Total & 47 & 100 \\
\hline Assuntos preferidos nas conversas & $\mathbf{N}$ & $\mathbf{\%}$ \\
\hline Brincadeiras & 13 & 24,6 \\
Escola & 13 & 24,6 \\
Música, filmes, vídeos, programas de TV, artistas & 9 & 17 \\
etc. & & \\
Coisas do dia a dia (da vida) & 6 & 11 \\
Piadas e gozações & 5 & 9,5 \\
Garotos/garotas, namorados/namoradas & 3 & 5,7 \\
Outros & 4 & 7,6 \\
Total & 53 & 100 \\
\hline Dal & &
\end{tabular}

Fonte: Dados da pesquisa.

As brincadeiras, as atividades e os assuntos das conversas dos estudantes com seus amigos corroboram a ideia de Garcia (2005) de que os vínculos de amizade são perpassados pelos elementos históricos, culturais e econômicos com que as crianças convivem. Tais vínculos têm influência tanto do contexto mais imediato de convivência, a exemplo da família, escola e vizinhança, como de fatores mais distantes, como a mídia.

$\mathrm{O}$ ambiente escolar possibilita o desenvolvimento de atividades em grupo, instiga a cooperação entre os pares e promove momentos de brincadeira e recreação, contribuindo para a constituição de vínculos afetivos. Esses são elementos importantes para a constituição do sujeito e do afeto positivo, assim como para a aculturação do estudante estrangeiro no contexto escolar brasileiro de fronteira.

\section{Preferências positivas, negativas e neutras dos estudantes}

Nas relações, as pessoas expressam três sinais possíveis: positivo (aceitação), negativo (rechaço) e neutro (ambivalente) (BUSTOS, 1979). Partindo desse pressuposto, utilizou-se o teste sociométrico para observar as escolhas positivas, negativas e neutras dos estudantes na hora de executar tarefas na sala de aula. Para cada um desses domínios, o estudante indicou três escolhas em ordem decrescente e as justificou. Optou-se por 
apresentar a quantidade das eleições da primeira escolha positiva, da negativa e da neutra (Gráfico 1).

Gráfico 1 - Eleições dos estudantes

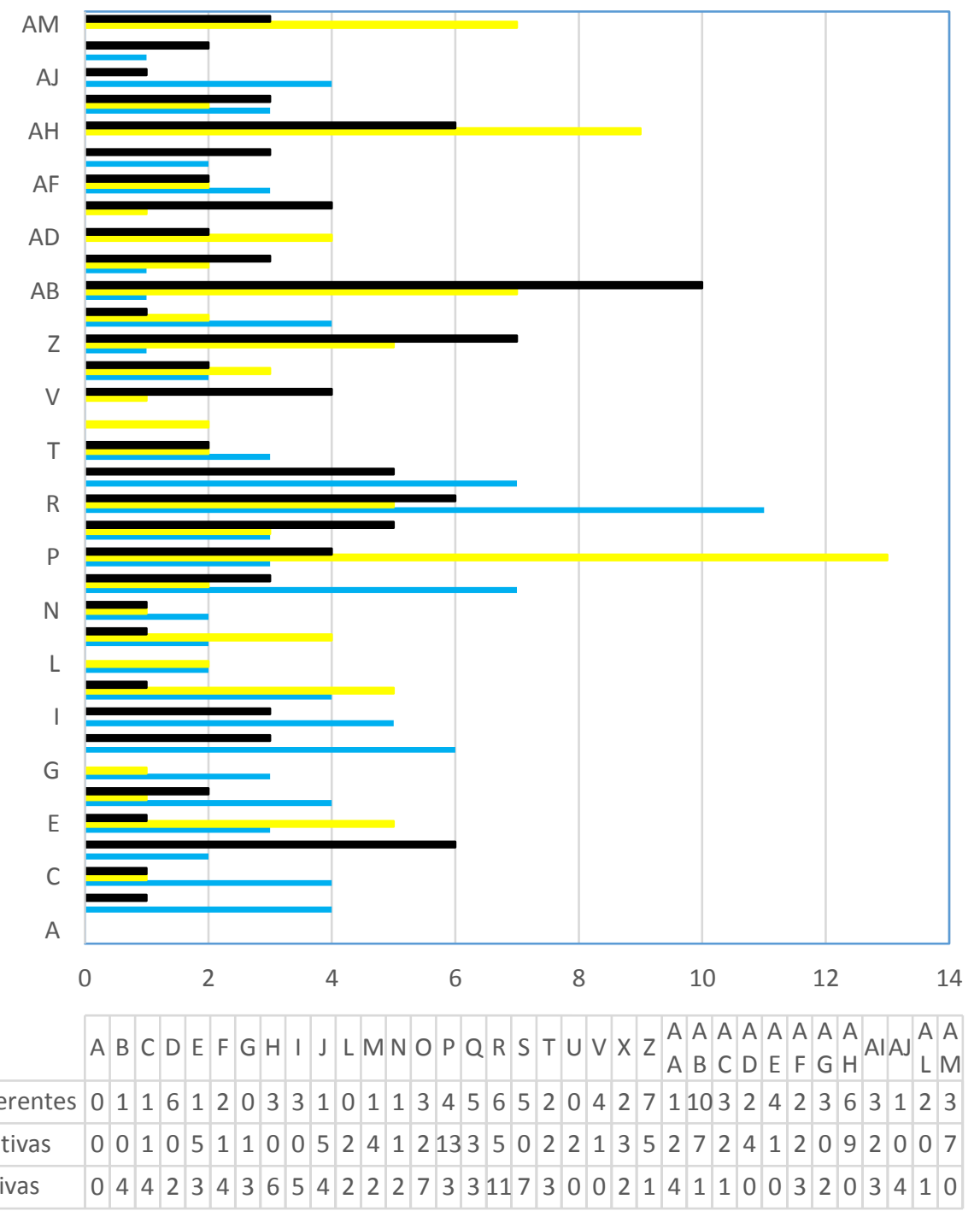

Fonte: Dados da pesquisa.

No Gráfico 1, que trata de frequência de escolhas segundo um critério sociométrico, as escolhas positivas foram os estudantes indicados para realizar uma tarefa juntos; as negativas, os que foram indicados como não escolhidos; e as neutras, os que não foram considerados nem de maneira positiva nem negativa. Observa-se que os estudantes AM, AH e P tiveram um número mais elevado de eleições negativas; já nas eleições indiferentes, $\mathrm{AB}$ e $\mathrm{Z}$ foram mais indicados; e, nas eleições positivas, destacaram-se $\mathrm{O}, \mathrm{S}$ e $\mathrm{R}$, sendo que as duas últimas apontaram que falavam o idioma espanhol ou guarani e a 
última falava nesses idiomas com os amigos. O estudante A que declarou conversar em espanhol, não foi indicado em nenhuma das eleições, mas apontou dois estudantes que falavam espanhol e/ou guarani e um que falava português. O estudante U teve duas eleições negativas e nenhuma indicação nas outras eleições.

A comunicação é culturalmente complexa, e alguns aspectos culturais podem levar algum tempo para ser dominados por migrantes internacionais. A cultura, incluindo a cultura social, e as habilidades linguísticas são elementos importantes para fazer amizade com pessoas de outras origens nacionais (GARCIA; PENSO, 2017), contribuindo para a adoção da integração como estratégia de aculturação. A integração leva a melhores resultados de adaptação e implica competência que vem do próprio grupo étnico e cultural e da sociedade acolhedora, ao passo que a estratégia de marginalização é considerada a menos adaptável, implicando pouca competência e ausência de apoio de qualquer grupo cultural; portanto, os riscos de dificuldades de adaptação são maiores (SAM; BERRY, 2010).

Foi solicitado que o estudante justificasse cada escolha. As justificativas da primeira preferência negativa, ou seja, da não escolha do colega de sala para realizar uma tarefa na escola incluíram, sobretudo, o comportamento de bagunçar em sala de aula, o uso indevido da inteligência, a ausência de contato com o colega e os conflitos com os pares e professores. Já as justificativas da escolha do primeiro colega na posição neutra se aproximaram das indicadas nas eleições negativas. Foram ancoradas na falta de empenho e compreensão das atividades, na não realização das tarefas propostas, na ausência de interação com o colega, na existência de brigas e conflitos e, também, na falta de uma relação de amizade.

Tem-se como desafio a superação dos conflitos entre os estudantes, sendo a amizade um possível elemento para melhorar as relações interpessoais nesse contexto. A partir da discussão filosófica da amizade, tomando-a como o exercício da ética e da política no contexto educacional, Carvalho (2015) considerou-a fundamental para construir uma boa relação perante a pluralidade, a diversidade e a singularidade presentes na sala de aula. A amizade pode ser uma prática e uma maneira de transformar a sala de aula num espaço aberto a relações intersubjetivas renovadas, além de uma saída para amenizar a violência e os conflitos escolares (CARVALHO, 2010). Tal ideia é corroborada com as justificativas para a primeira escolha do colega para realizar uma 
tarefa juntos, que incluíram ser amigo e/ou melhor amigo, ser uma pessoa especial, amorosa, divertida, ótima e solidária, e o prazer de estar juntos.

A amizade favorece a boa convivência, a criação de vínculos, a vida feliz, alegre e prazerosa. Além disso, colabora para a partilha das tristezas e alegrias e promove a confiança (CARVALHO; LUENGO, 2015). A confiança foi sinalizada anteriormente pelos estudantes, sendo também apontada a inteligência, a responsabilidade, o esforço, a interação, a cooperação e a ajuda do colega como elementos balizadores de suas escolhas.

Além das características cognitivas que influenciaram as escolhas dos estudantes, foram indicados os elementos relacionados à cordialidade, ao companheirismo e à diversão. Assim, ser "legal”, divertido e atencioso também foi relatado como justificativa dos estudantes para a escolha do colega para a realização de uma atividade juntos.

A partir dos relatos, observa-se a pluralidade no espaço de sala de aula. Há situações de conflito, mas também de harmonia e solidariedade que suscitam a constituição de relações entre os estudantes brasileiros e paraguaios. Isso promove a visão do estudante como um ser ético, com possibilidade e capacidade de viver e conviver com os demais e de respeitar as singularidades e diferenças, em que a amizade favorece o acolhimento e o cuidado com os demais.

A amizade internacional, que inclui relacionamentos entre duas pessoas vindas de países diferentes, cidadãos locais e imigrantes internacionais, se associa à educação em diferentes níveis (GARCIA; PENSO, 2016). Os sociogramas da ordem de preferência dos colegas de turma possibilitam observar isso e outros elementos das interações no contexto de sala de aula (Figuras 1, 2 e 3). 
Figura 1 - Sociograma da primeira opção nas eleições positivas

E

$\mathbf{C}$

C

$\mathbf{O}$

$\mathbf{S}$

$-$

$\mathbf{R}$

I

S

$\mathbf{T}$

A

C
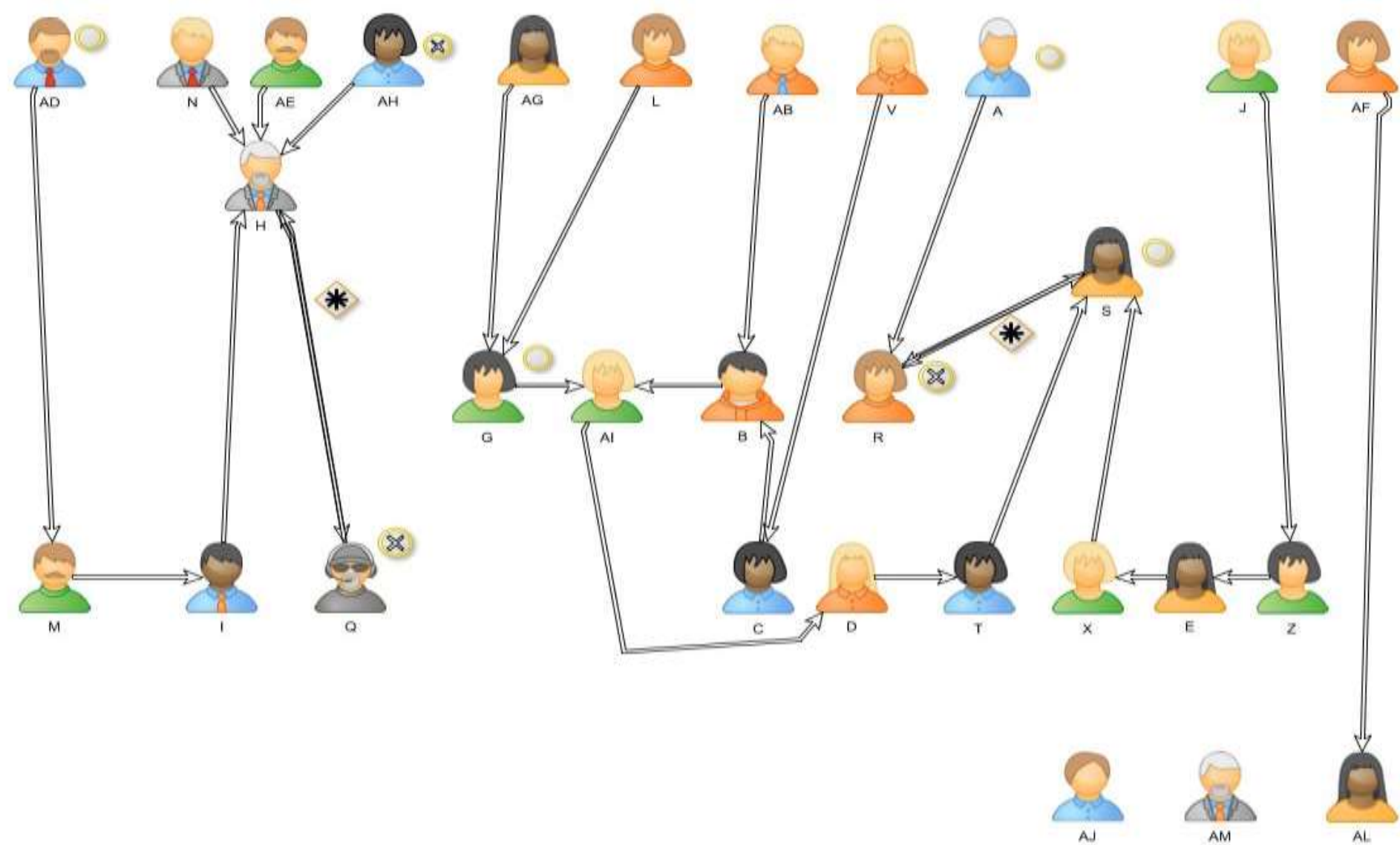

\section{Escolhas mútuas.}

Estudantes de ascendência paraguaia ou paraguaio e brasiguaio.

Estudantes de ascendência paraguaia ou paraguaio e brasiguaio que falavam espanhol ou guarani com os amigos.

Fonte: Dados da pesquisa. 
Na primeira fileira da parte superior desse sociograma, tem-se um número razoável de estudantes $(n=14)$ que não foram escolhidos e, na inferior, os estudantes ausentes $(\mathrm{n}=3)$. Observam-se três líderes e subgrupos, uma dupla (AF e AL) e dois estudantes isolados (AJ e AM). É visível também a relação intercultural, a exemplo de AC (que fala outro idioma) com P (que fala português); $\mathrm{AH}$ (que fala outro idioma) com $\mathrm{H}$ (que fala português); $\mathrm{G}$ (que fala outro idioma) com $\mathrm{AJ}$ (que fala português); e $\mathrm{S}$ (que fala outro idioma) com X (que fala português), além da escolha mútua entre H (brasileiro) e Q (de descendência paraguaia, que fala outro idioma com os amigos).

Também se verifica a reciprocidade na escolha entre $\mathrm{S}$ e $\mathrm{R}$ - ambas falam outro idioma além do português - e entre P e AA, que falam, ambos, em português com seus amigos. Na posição de destaque, está $\mathrm{P}$, escolhido por $\mathrm{T}$ e $\mathrm{X}$. Estes últimos falavam na língua portuguesa com seus amigos.

Carvalho e Luengo (2017) consideram a amizade como a capacidade e a disposição para viver com o outro, aspirando àquilo que se crê que seja bom e realizado por causa desse outro; trata-se de um sentimento e uma virtude indispensáveis à vida, sobretudo à vida ética. No contexto de escolas inclusivas, quando a amizade é considerada, "as crianças, nas relações com os outros, podem ser vistas, ouvidas, acalentadas e se tornar solidárias para com todos os semelhantes" (CARVALHO; LUENGO, 2017, p. 612).

Crianças menos tendenciosas e preconceituosas demonstraram ter mais interações e companhias e perceberam seus amigos de maneira mais positiva. Comparadas com seus colegas de classe mais tolerantes, as crianças brancas com índices elevados de preconceito apresentaram a tendência de excluir mais colegas de origem étnica divergente da sua e consideraram sua amizade em índices mais baixos de qualidade (ABOUD; MENDELSON; PURDY 2003). As escolhas dos estudantes brasileiros e paraguaios sinalizam nessa direção, sobretudo as estudantes $\mathrm{R}$ e $\mathrm{S}$, que mantêm relações com estudantes brasileiros e de ascendência paraguaia ou paraguaios (Figura 2). 
Figura 2 - Sociograma de segunda opção nas eleições positivas

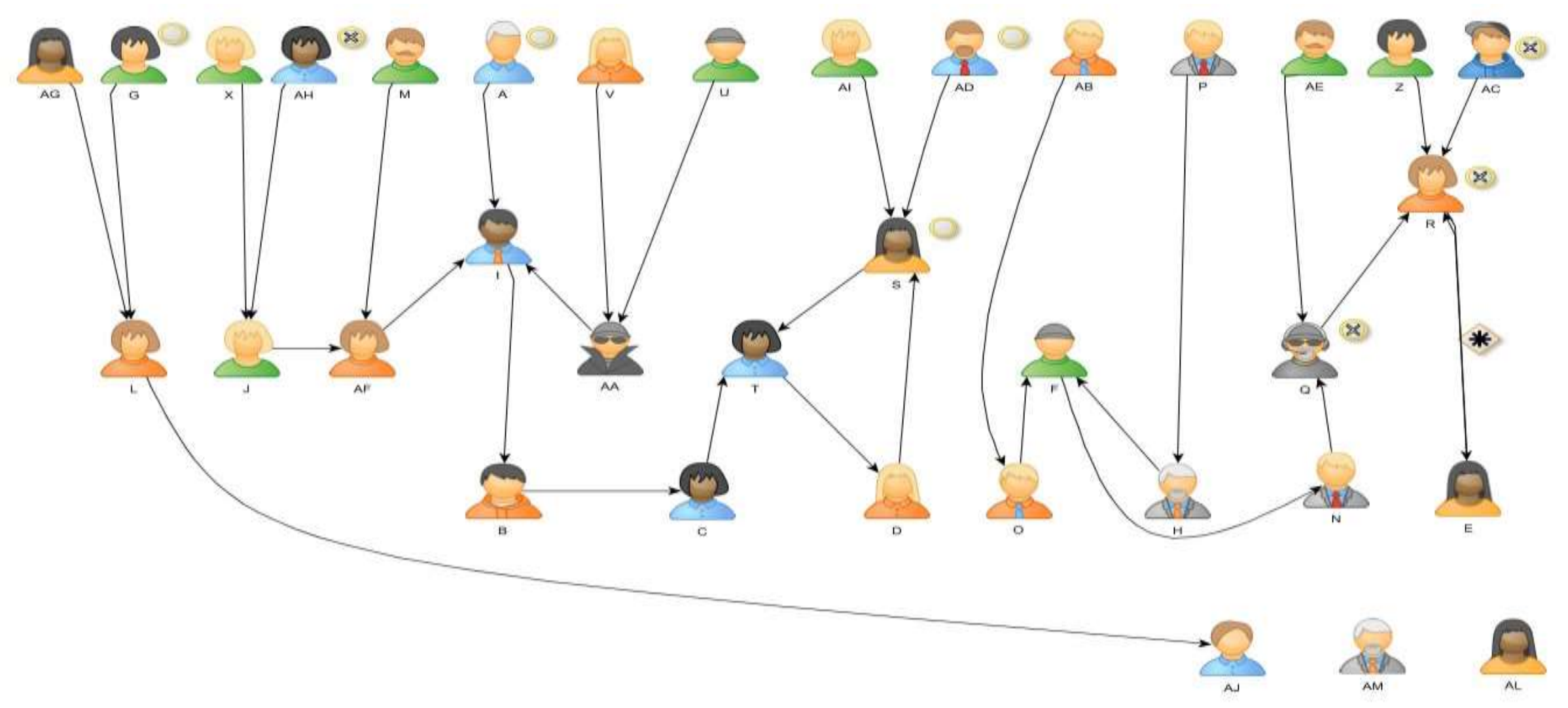

Escolhas mútuas.

Estudantes de ascendência paraguaia ou paraguaio e brasiguaio.

(as) Estudantes de ascendência paraguaia ou paraguaio e brasiguaio que falavam espanhol ou guarani com os amigos.

Fonte: Dados da pesquisa. 
Observam-se, nesse sociograma de segunda opção, 15 estudantes que fizeram eleições e não foram escolhidos, dois grupos maiores, em que os membros são interligados pelos líderes, um subgrupo menor e dois estudantes isolados, AM e AL. As estudantes $\mathrm{S}, \mathrm{R}$ e $\mathrm{Q}$ foram escolhidas e/ou escolheram estudantes brasileiros que falavam português e de origem paraguaia que falavam outros idiomas com seus amigos. Isso sugere a integração como estratégia de aculturação, já que elas, possivelmente, mantêm relações com estudantes das culturas brasileira e paraguaia.

Destaca-se a escolha mútua entre $\mathrm{R}$ e $\mathrm{E}$, sugerindo a relação intercultural de amizade, cooperação, reciprocidade e diversão, visível nas justificativas: "porque ela é minha amiga, inteligente, legal e ela sempre me ajuda quando eu preciso e quando eu choro ela está sempre do meu lado" (R); e "é muito engraçada" (E). R também mantém relação de amizade com Q, que a considerou "melhor amiga, inteligente e que faz as tarefas". Esse achado corrobora a ideia de que a cultura acolhedora se relaciona com o ajustamento escolar (VALDIVIA; SCHNEIDER; CARRASCO, 2016).

Através da simbolização numérica e gráfica (sociogramas), foram identificados os vínculos entre os estudantes brasileiros e paraguaios. Na análise dos sociogramas, é possível sugerir que $\mathrm{R}$ adotou a integração como estratégia de aculturação, tendo em vista que mantém relações de amizade com estudantes de origem brasileira e paraguaia e que declarou falar espanhol com seus amigos. A interação positiva entre estudantes, independente de língua ou de origem, é relevante, pois instiga o respeito à diferença no contexto escolar. Consequentemente, possibilita o início de modificações de atitudes de professores (BERGER, 2015b).

A coexistência de línguas diferentes no contexto escolar de Ponta Porã foi descrita pelos professores como um problema em relação à comunicação com os estudantes e responsáveis nesses espaços. Ocorreu um índice significativo de reprovação desses estudantes, justificada por uma professora em decorrência “[...] da circulação do espanhol e do guarani na escola. Embora se observe uma premissa equivocada por parte da educadora, o dado revela uma atitude desfavorável em relação a presença dessas línguas nos espaços de instrução brasileiros" (BERGER, 2015a, p.179).

A escola brasileira anulou as diferenças em seu interior, haja vista que, por muitos anos, os conteúdos trabalhados baseavam-se, principalmente, nos materias didáticos enviados pela Ministério da Educação. Mesmo os educadores e as autoridades da escola reconhecendo a pluralidade cultural, a pedagogia usada continuou monolíngue, e esse 
problema ainda carece de "uma ação que inclua, de fato, as crianças estrangeiras no cotidiano escolar brasileiro, reconhecendo e respeitando suas características culturais de origem" (PEREIRA, 2014, p. 103).

Na Figura 3, observa-se que 15 estudantes, ou seja, 50\% do total geral, fizeram escolhas e não foram escolhidos e que um dos estudantes ausentes foi escolhido por duas estudantes presentes. A amizade intercultural entre $\mathrm{C}$ e $\mathrm{S}$, entre os líderes $\mathrm{R}$ e $\mathrm{O}$, e entre Q e O evidencia a escolha de estudantes brasileiros por parte dos paraguaios e vice-versa. Nesse aspecto, as amizades entre imigrantes internacionais e estudantes nativos é o esperado (GARCIA; PENSO, 2016). 
Figura 3 - Sociograma de terceira opção nas eleições positivas

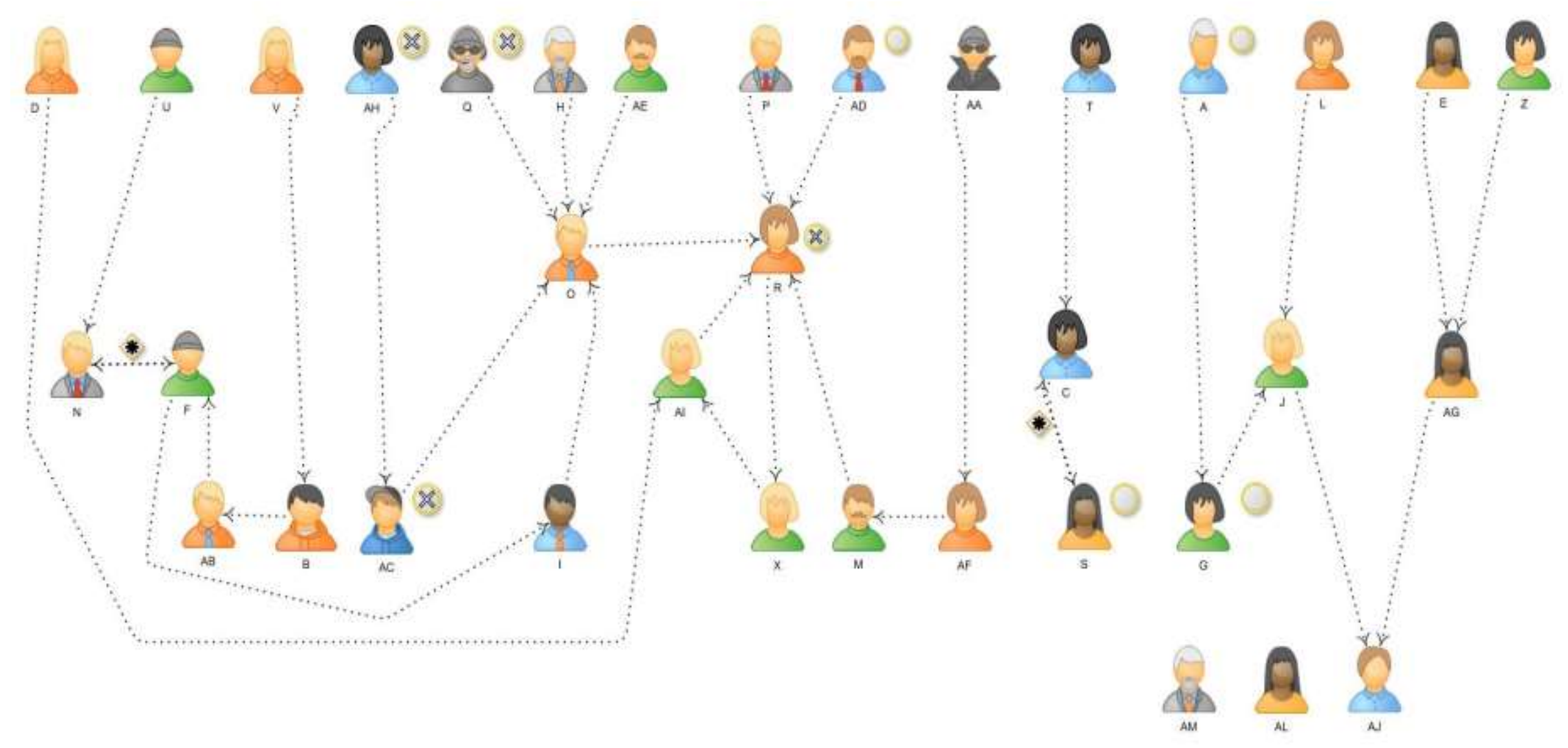

* Escolhas mútuas.

Estudantes de ascendência paraguaia ou paraguaio e brasiguaio.

(s) Estudantes de ascendência paraguaia ou paraguaio e brasiguaio que falavam espanhol ou guarani com os amigos.

Fonte: Dados da pesquisa. 
O status dos estudantes, que se constituiu como um dos recursos de identificação da amizade de estudantes brasileiros e paraguaios no contexto de sala de aula na região de fronteira, corrobora a ideia de Garcia e Penso (2016) de que a educação está associada à amizade internacional e de que os estudantes internacionais geralmente têm amigos nacionais. Assim, os dados apontam uma relação entre estudantes paraguaios e brasileiros.

As escolhas mútuas entre brasileiros e paraguaios, a exemplo de $\mathrm{H}$ e Q (na Figura 1), R e E (na Figura 2) e $\mathrm{S}$ e $\mathrm{C}$ (na Figura 3), demonstram que há relações interculturais e que, possivelmente, ocorrem influências mútuas. Os grupos em aculturação trazem suas características culturais e psicológicas, influenciando e sendo influenciados pelas características do seu novo contexto de convivência. A aculturação envolve a interação e possibilita ações e reações à situação de contato em diversos ambientes, como nas escolas, que atendem estudantes oriundos de diversas culturas.

$\mathrm{Na}$ análise das Figuras 1, 2 e 3, observa-se a interação e relação de amizade entre estudantes brasileiros e de ascendência paraguaia ou paraguaios. Verifica-se, também, que as posições de R, S e Q sugerem a adoção da integração como estratégia de aculturação. A condição para a integração é uma sociedade aberta e inclusiva, com interação pautada no respeito e na aceitação de diferenças e da diversidade cultural, com uma ideologia intercultural positiva, níveis relativamente baixos de preconceito, atitudes positivas mútuas entre grupos culturais e um sentimento de apego ou identificação com a sociedade maior por parte dos grupos (BERRY, 1997a).

Uma análise mais minuciosa dos sociogramas corrobora a ideia de amizade como um tipo de laço marcado por vinculações recíprocas, amorosidade e, sobretudo, diferença como elemento de enfrentamento à homogeneização. A amizade pode proporcionar ruptura de formato e, no contexto escolar, principalmente na sala de aula, revitalizar o sentido de espaço comum, propício à experiência da alteridade, diferença e aprendizagem, com possibilidade de ter a marca de todos (SILVA, 2018).

\section{Considerações finais}

Em escolas de Ponta Porã, a interculturalidade é perceptível. Neste estudo, observou-se o uso de português, espanhol e guarani na relação de amizade, mas a minoria dos estudantes falava estes últimos com seus amigos, o que indica desafios para a educação intercultural. Por isso, é preciso efetivar ações educativas que garantam o espaço das línguas nas relações 
interpessoais de amizade e na própria escola, que é potencial para atitudes de respeito à diferença e reconhecimento da pluralidade cultural.

Contudo, havia relação de amizade entre estudantes de origem paraguaia com brasileiros, inclusive ocorrendo escolhas recíprocas entre eles. Além disso, os sociogramas apontaram a existência de subgrupos na sala de aula, com escolhas mútuas, estudantes que só escolheram, mas não foram escolhidos, e tanto estudantes brasileiros como paraguaios ou de ascendência paraguaia na posição de líderes.

As justificativas usadas para a realização de uma tarefa juntos têm relação com a aproximação e com os vínculos afetivos, mas também com o perfil dos estudantes: foi preferido o estudante percebido como compromissado com as tarefas, responsável, cooperador, inteligente, engraçado, divertido e amigo.

Os dados apontaram que a escola é um contexto favorável para a constituição da amizade dos estudantes brasileiros e de ascendência paraguaia ou paraguaios. Nesse local, eles conversam acerca de diversos assuntos, estudam e jogam futebol, queimada e vôlei, e brincam esconde-esconde, além de jogos no celular e no videogame. As conversas gravitam em torno das brincadeiras e dos compromissos escolares, mas também do namoro, da moda, da música, de fazer bagunça e rir. Em síntese, os dados sugerem que há amizade intercultural entre Brasil e Paraguai na escola de fronteira seca.

No entanto, esses achados devem ser observados com cautela, pois não abrangem a maioria de estudantes estrangeiros em escolas brasileiras localizadas nessa região de fronteira seca. Além disso, não se verificou a influência do tempo de estudos no Brasil, assim como a ação pedagógica e de familiares na constituição dessa relação de amizade. Nesse sentido, sugere-se a ampliação desta pesquisa noutras turmas e escolas; e a verificação se a quantidade de anos de permanência do estudante de ascendência paraguaia e/ou paraguaio no Brasil, a ação pedagógica acolhedora da interculturalidade com vistas à integração como estratégia de aculturação e a família influenciam a amizade intercultural na região de fronteira.

\section{Referências}

ABOUD, Frances E.; MENDELSON, Morton J.; PURDY, Kelly T. Cross-race peer relations and friendship quality. International Journal of Behavioral Development, v. 27, n. 2, p. 165-173, 2003.

BERGER, Isis Ribeiro. Atitudes de professores brasileiros diante da presença do espanhol e do guarani em escolas na fronteira Brasil-Paraguai: elemento à gestão de línguas. Signo y Seña, n. 28, p. 169-185, 2015a. Disponível em: <http://revistas.filo.uba.ar/index.php/sys/article/view/264/232>. Acesso em: 2 dez. 2017. 
BERGER, Isis Ribeiro. Experiências e ações de política linguística no âmbito do observatório da educação na fronteira. Revista do GEL, v. 12, n. 2, p. 138-163, 2015b. Disponível em: <https://revistadogel.gel.org.br/rg/article/view/465/438>. Acesso em: 2 dez. 2017.

BERRY, John W. Acculturation: adaptation or development? Commentaries, p. 52-55, 1997a. Disponível em: 〈http://www.iaccp.org/sites/default/files/schongflug_1997.pdf〉. Acesso em: 2 dez. 2017.

BERRY, John W.. Immigration, acculturation, and adaptation. Applied Psychology: an International Review, v. 46, n. 1, p. 5-68, 1997 b.

BERRY, John W. et al. Introduction to cross-cultural psychology. In: Cross-cultural psychology research and applications. 2. ed. Cambridge: Cambridge University Press, 2002. p. 1-16. Disponível em: <https://tsu.ge/data/file_db/faculty_psychology/CrossCultural\%20Psychology.pdf >. Acesso em: 10 jan. 2017.

BUSTOS, Dalmiro Manuel. O teste sociométrico: fundamentos, técnica e aplicações. Tradução de Antonio Marcello Campedelli. São Paulo: Brasiliense, 1979.

CARVALHO, Alonso Bezerra de. A relação professor-aluno e a amizade na sala de aula: por uma outra formação humana na escola. Revista Espaço Acadêmico, v. 14, n. 169, p. 23-33, 2015. Disponível em: <http://periodicos.uem.br/ojs/index.php/EspacoAcademico/article/view/27889/14690>. Acesso em: 10 jan. 2018.

CARVALHO, Alonso Bezerra de Alteridade e amizade na educação: a sala de aula como espaço ético. In: Congresso InTERnACIONAL de FILOSOFIA E EdUCAÇÃo, V., 2010, Caxias do Sul. Anais Congresso Internacional de Filosofia e Educação, Caxias do Sul: Universidade de Caxias do Sul, 2010. Disponível em: <https://www.ucs.br/.../Alteridade\%20e\%20amizade\%20na\%20educacao_a\%20sala\%20>. Acesso em: 10 jan. 2018.

CARVALHO, Alonso Bezerra de; LUENGO, Fabiola Colombani. A amizade na sala de aula e a educação inclusiva: reflexões filosóficas. Revista Educação Especial, v. 30, n. 59, 2017. Disponível em: <https://periodicos.ufsm.br/educacaoespecial/article/view/28081/pdf>. Acesso em: 29 nov. 2017.

CARVALHO, Alonso Bezerra de; LUENGO, Fabiola Colombani.. A sala de aula como espaço de encontro: ética e amizade na prática pedagógica. Actas del Tercer Congreso de Filosofía de la Educación, v. 3, 2015: 1635-1648. Disponível em: < http://filosofiaeducacion.org/actas/index.php/act/article/view/156> Acesso em: 10 jan. 2018.

DEBIAGGI, Sylvia Dantas. Introdução. In: DEBIAGGI, Sylvia Dantas; PAIVA, Geraldo José (orgs.). Psicologia, e/imigração e cultura. São Paulo: Casa do Psicólogo, 2004. p. 135164.

GARCIA, Agnaldo. Psicologia da amizade na infância: uma introdução. Vitória: UFES, 2005. Disponível em: <https://agnaldogarcia.files.wordpress.com/2010/12/agnaldo_garcia__livro-psicologia-da-amizade-na-infc3a2ncia.pdf >. Acesso em: 29 nov. 2017. 
GARCIA, Agnaldo; PENSO, Maria Aparecida. The context of international friendships: migration and international education. In: GARCIA, Agnaldo. International friendships: the interpersonal basis of a worldwide community. Nescastle upon Tyne: Cambridge Scholars, 2016. p. 12-25.

MORENO, Jacob Levy. Quem sobreviverá? Fundamentos da sociometria, da psicoterapia de grupo e do sociodrama. Tradução: Denise Lopes Rodrigues e Márcia Amaral Kafuri. Goiânia: Dimensão, 1994. v. 2.

NETO, Félix Fernando Monteiro. Estudos de psicologia intercultural: nós e outros. 3. ed. Lisboa: Fundação Calouste Gulbenkian, 2012a. v. 1.

NETO, Félix Fernando Monteiro. Estudos de psicologia intercultural: nós e outros. 3. ed. Lisboa: Fundação Calouste Gulbenkian, 2012b. v. 2.

ORGANIZAÇÃO DAS NAÇÕES UNIDAS PARA A EDUCAÇÃO, A CIÊNCIA E A CULTURA (UNESCO). Educação para a cidadania global: tópicos e objetivos de aprendizagem. Brasília, 2016. Disponível em:

<http://unesdoc.unesco.org/images/0024/002448/244826POR.pdf>. Acesso em: 10 set. 2017.

PEREIRA, Jacira Helena do Valle. Educação na fronteira: o caso Ponta Porã (MS) e Pedro Juan Caballero (PY). Papéis, Revista do Programa de Pós-Graduação em Estudos de Linguagens, v. 18, n. 36, p. 93-106, 2014. Disponível em:

<http://seer.ufms.br/index.php/papeis/article/view/3015>. Acesso em: 20 jan. 2017.

SAM, David L.; BERRY, John W. Acculturation: when individuals and groups of different cultural backgrounds meet. Perspectives on Psychological Science, v. 5, n. 4, p. 472-481, 2010. Disponível em:

<http://journals.sagepub.com/doi/abs/10.1177/1745691610373075?journalCode=ppsa>. Acesso em: 2 mar. 2018.

SILVA, Rafael Bianchi. Amizade, diferença e educação: reflexões a partir de Zygmunt Bauman. Educação \& Realidade, v. 43, n. 1, p. 115-129, 2018. Disponível em:

<http://www.scielo.br/scielo.php?script=sci_arttext\&pid=S2175-

62362018000100115\&lng=en\&nrm=iso>. Acesso em: 29 jan. 2018.

VALDIVIA, Ibis M. Alvarez; SCHNEIDER, Barry H.; CARRASCO, Cecilia Villalobos. School adjustment and friendship quality of first and second generation adolescent immigrants to Spain as a function of acculturation. Journal of Adolescent Research, v. 31, n. 6, p. 750-777, 2016. 